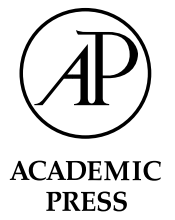

\title{
Vibrational spectroscopy of cis- and trans-formic acid in solid argon
}

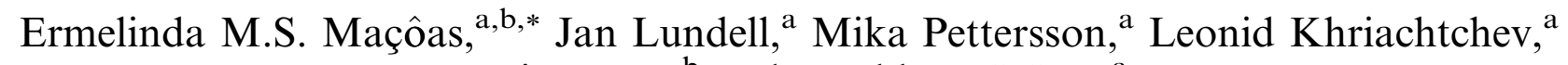 \\ Rui Fausto, ${ }^{\mathrm{b}}$ and Markku Räsänen ${ }^{\mathrm{a}}$ \\ ${ }^{a}$ Laboratory of Physical Chemistry, University of Helsinki, P.O. Box 55 (A.I. Virtasen aukio 1), FIN-00014 Helsinki, Finland \\ ${ }^{\mathrm{b}}$ Department of Chemistry (CQC), University of Coimbra, P-3004-535 Coimbra, Portugal
}

Received 26 September 2002; in revised form 19 December 2002

\begin{abstract}
Absorption spectra of cis and trans conformers of formic acid ( $\mathrm{HCOOH})$ isolated in solid argon are analyzed in the mid-infrared $\left(4000-400 \mathrm{~cm}^{-1}\right)$ and near-infrared $\left(7800-4000 \mathrm{~cm}^{-1}\right)$ regions. The $\mathrm{HCOOH}$ absorption spectrum reveals matrix-site splitting for the trapped molecule. Narrowband tunable infrared radiation is used to pump a suitable vibrational transition of the trans conformer in order to promote site-selectively the conversion to the $c i s$ conformer and separate the spectral features of each site group. Several anharmonic resonances are identified for both conformers. The results of anharmonic vibrational ab initio calculations (CC-VSCF) for the trans and cis conformers of formic acid are reported and compared with the experimental spectra.
\end{abstract}

(C) 2003 Elsevier Science (USA). All rights reserved.

\section{Introduction}

Formic acid $(\mathrm{HCOOH})$ is the simplest organic acid exhibiting rotational isomerism with respect to rotation around the single $\mathrm{C}-\mathrm{O}$ bond. It is a molecule of astrophysical [1] and atmospheric [2] relevance, and has a wide range of industrial applications [3]. Formic acid exists in two stable planar structures, the cis and trans conformers shown in Fig. 1, with $0^{\circ}$ and $180^{\circ} \mathrm{H}-\mathrm{C}-\mathrm{O}-\mathrm{H}$ dihedral angles, respectively. The trans form is the most stable and the predominant one in the gas phase. Gas phase [4-8] and matrix-isolated [9-12] trans-formic acid and its isotopomers have been the subject of many spectroscopic studies in the mid-infrared region (midIR). Near-infrared (near-IR) spectroscopic data for the gaseous trans-HCOOH and its deuterated analogues are also available [13]. Recently, a detailed analysis of the gas-phase vibrational spectrum of trans-HCOOH appeared, reporting new overtone and combination data [14]. To the best of our knowledge no near-IR data of matrix-isolated formic acid has been reported yet.

The first reliable identification of cis- $\mathrm{HCOOH}$ was made in the gas phase by Hocking, where the microwave

\footnotetext{
* Corresponding author.

E-mail address: emacoas@qui.uc.pt (E.M.S. Maçôas).
}

spectra of isotopically substituted species of cis-formic acid were reported [15]. The lack of experimental data concerning this conformer is not surprising considering the relative energy difference of $1365 \mathrm{~cm}^{-1}$ between the two conformers [15], leading to a Boltzmann population ratio of $P_{\text {cis }}: P_{\text {trans }} \approx 10^{-3}$ at $298 \mathrm{~K}$. The thermal decomposition of gaseous formic acid at moderately high temperatures complicates the thermal enhancement of the population of the cis form [16]. The assignment of 8 out of the 9 IR-active fundamentals and a few overtones and combination modes of cis-formic acid in an argon matrix have been previously reported [17]. In that work, narrowband tunable near-IR radiation was used to convert the trans conformer into the cis form by pumping the first $\mathrm{OH}$ stretching overtone at ca. $6934 \mathrm{~cm}^{-1}$. This excitation is sufficient to surmount the estimated torsional energy barrier (values ranging from $\approx 4200$ to $\left.4800 \mathrm{~cm}^{-1}[15,18,19]\right)$. It was found that in an argon matrix at $15 \mathrm{~K}$ cis-HCOOH tunnels back to trans$\mathrm{HCOOH}$ with a rate of ca. $2 \times 10^{-3} \mathrm{~s}^{-1}$, limiting the data collection time [17,20].

Splitting of IR absorption bands of matrix-isolated species is a well-known phenomenon usually called matrix-site effect. This splitting is caused by different local environments of the trapped species and potentially provides a way to study local matrix morphology. 


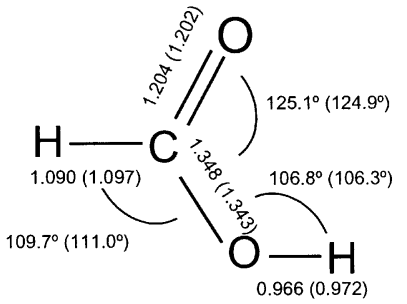

trans

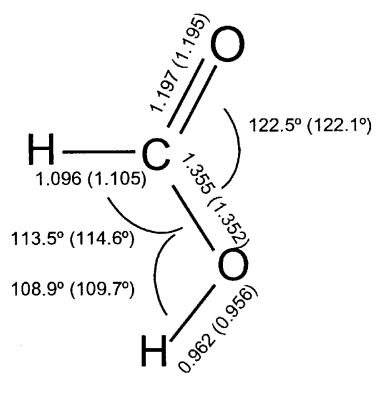

cis
Fig. 1. The two stable conformers of formic acid; cis-HCOOH being $1365 \mathrm{~cm}^{-1}$ above trans-HCOOH [15]. The optimized MP2/6$311++\mathrm{G}(2 \mathrm{~d}, 2 \mathrm{p})$ geometrical parameters are given together with the experimental values from [30] in parenthesis. Angles are in degrees and bond length in angstroms.

In our studies of $\mathrm{HONO}$ and $(\mathrm{FCO})_{2}$ in rare-gas matrices [21,22], it was found that the interconversion of the isomers with narrowband IR pumping is site-selective and no exchange between site groups was seen. This concept of site-selective optical pumping is also used in the present study.

In this work, the mid-IR absorption spectra of cisand trans-HCOOH and DCOOH, as well as the near-IR absorption spectra of cis- and trans- $\mathrm{HCOOH}$, isolated in different sites in argon matrices at $8 \mathrm{~K}$ are analyzed. The near-IR spectra of the matrix-isolated trans-DCOOH and trans-HCOOD isotopomers are also studied. Additionally, the anharmonic vibrational frequencies for both isomers of $\mathrm{HCOOH}$ and $\mathrm{DCOOH}$, derived from correlation-corrected vibrational self-consistent-field calculations (CC-VSCF) [23-26] based on the MP2/6$311++\mathrm{G}(2 \mathrm{~d}, 2 \mathrm{p})$ computed potential energy surfaces, are reported and the performance of the method is discussed.

\section{Experimental}

The gaseous samples were prepared by mixing formic acid (KEBO LAB, $>99 \%$ ) or its isotopomers (HCOOD and DCOOD, IT Isotop, 95-98\%), degassed by several freeze-pump-thaw cycles, with high purity argon (AGA, 99.9999\%), typically in the $1: 1000$ proportion. The DCOOH species was obtained from DCOOD by exchange with $\mathrm{H}_{2} \mathrm{O}$ adsorbed on the inner surface of the sample container and the deposition line. In this way DCOOD:DCOOH ratios of $\approx 1: 5$ in the matrix samples were obtained. The gaseous mixtures were deposited onto a cooled CsI substrate kept at $15 \mathrm{~K}$ in a closed cycle helium cryostat (APD, DE 202A) and subsequently cooled down to $8 \mathrm{~K}$. The IR absorption spectra (7900$450 \mathrm{~cm}^{-1}$ ) were measured with a Nicolet SX-60 FTIR spectrometer. A liquid nitrogen cooled MCT detector and a $\mathrm{KBr}$ beamsplitter were used to record the mid-IR spectra, with unapodized spectral resolutions from 0.25 to $1.0 \mathrm{~cm}^{-1}$, and a nitrogen cooled InSb detector and a quartz beamsplitter were used for the near-IR spectra, with a spectral resolution of $0.5 \mathrm{~cm}^{-1}$. Typically 128 and 500 interferograms were coadded for the mid-IR and near-IR spectra, respectively.

Tunable $(225 \mathrm{~nm}-4 \mu \mathrm{m})$ pulsed IR radiation provided by an optical parametric oscillator (OPO Sunlite, Continuum, with IR and UV extension) was used to induce the trans $\rightarrow$ cis isomerization of $\mathrm{HCOOH}$ and $\mathrm{DCOOH}$. The pulse duration was ca. $5 \mathrm{~ns}$ with a linewidth of $\sim 0.1 \mathrm{~cm}^{-1}$. A Burleigh WA-4500 wavemeter was used to control the OPO radiation wavelength, providing an absolute accuracy better than $1 \mathrm{~cm}^{-1}$. Without pumping, the concentration of the cis conformer produced by irradiation of the trans form decreases by more than $70 \%$ during the time needed to record the spectra. In order to maintain a sufficiently large concentration of the cis conformer during long measurements, the IR absorption spectra were recorded under simultaneous IR pumping. For this purpose the pumping beam was nearly parallel to the spectrometer beam and interference filters were used to prevent the scattered laser radiation from reaching the detector. A band pass filter transmitting in the $7900-4000 \mathrm{~cm}^{-1}$ region was used to record the spectrum while irradiating the sample in the $\mathrm{OH}$ stretching fundamental region of trans $-\mathrm{HCOOH}$ $\left(3560-3545 \mathrm{~cm}^{-1}\right)$ whereas the $3650-3400,3300-1000$, and $2000-500 \mathrm{~cm}^{-1}$ band pass filters were used to record the mid-IR spectra while pumping near-IR active bands. With these filters no interference of the laser radiation on the interferogram was detected.

\section{Computational method}

The equilibrium structures and harmonic vibrational frequencies of trans- and cis- $\mathrm{HCOOH}$ were calculated using the second-order Møller-Plesset perturbation (MP2) theory with the $6-311++G(2 d, 2 p)$ basis set. This basis set has been shown to be able to reproduce the experimental structural and vibrational properties of formic acid with an acceptable accuracy [27,28].

The anharmonic vibrational properties of various isotopomers of trans- and cis- $\mathrm{HCOOH}$ were studied by combining the electronic ab initio code GAMESS [29] with the vibrational self-consistent field (VSCF) method and its extension by corrections via second-order perturbation theory [23-26]. This correlation-corrected VSCF (CC-VSCF) method was used to solve the vibrational Schrödinger equation within the normal-mode coordinate system. This procedure involved representing the wavefunction as a product of one-dimensional functions and then solving the resulting equations selfconsistently. To make the integrals involved in the CCVSCF calculation more tractable and to reduce the 
number of electronic structure computations required, a pairwise coupling approximation was made to the potential in the normal-mode representation [24]. This approximation provided a grid of points in normalmode coordinates at which the potential energy was calculated. Each pair of normal modes was pictured with a 16-by-16 potential surface grid, leading to a total of 30816 points computed at the MP2/6-311++G(2d,2p) level of theory for each isotopomer.

\section{Results and discussion}

When the deposited samples are kept at $8 \mathrm{~K}$ under broadband globar irradiation it is possible to detect very weak bands belonging to the cis conformer for $\mathrm{HCOOH}, \mathrm{DCOOH}$, and HCOOD. The presence of the less stable conformer in the sample is due to the globar induced isomerization that leads to a photoequilibrium of the trans $\leftrightarrow$ cis interconversion under broadband IR irradiation [22]. The globar induced isomerization processes are suppressed by blocking the radiation above $2000 \mathrm{~cm}^{-1}$. In this case, the presence of the cis form was not detected.

The spectra of formic acid in an argon matrix clearly reveal two predominant trapping sites, here labeled as site 1 and site 2 . Pumping formic acid site-selectively allows us to distinguish the spectral features of each site. Figs. 2 and 3 present two regions of the mid-IR and near-IR difference spectra demonstrating the results of the site-selective pumping of trans-HCOOH. The photoinduced relative population of the cis conformers was typically $\approx 50 \%$.

\section{Mid-IR region}

The absorptions of trans-formic acid detected at $4183.6 \mathrm{~cm}^{-1}$ for site 1 and $4185.2 \mathrm{~cm}^{-1}$ for site 2 were used to excite vibrationally $\mathrm{HCOOH}$ and promote the site-selective rotamerization, enabling the collection of information about the mid-IR spectrum of both sites (Fig. 2). DCOOH was irradiated at 6933.3 and $6937.4 \mathrm{~cm}^{-1}$ in order to promote the photo-isomerization reactions in the corresponding sites 1 and 2. Table 1 shows the observed mid-IR absorptions for the two main sites for both conformers of $\mathrm{HCOOH}$ and $\mathrm{DCOOH}$ in solid argon together with the anharmonic computational predictions for the vibrational frequencies. The assignments made for both conformers of $\mathrm{HCOOH}$ and for trans-DCOOH agree with those reported in $[10,11,17]$. The spectral data for $c i s-\mathrm{DCOOH}$ are reported here for the first time. For some modes (e.g. $\mathrm{C}=\mathrm{O}$ stretching) the band belonging to the same site appear clearly splitted in several components. This is due to solid state perturbations on the vibrational

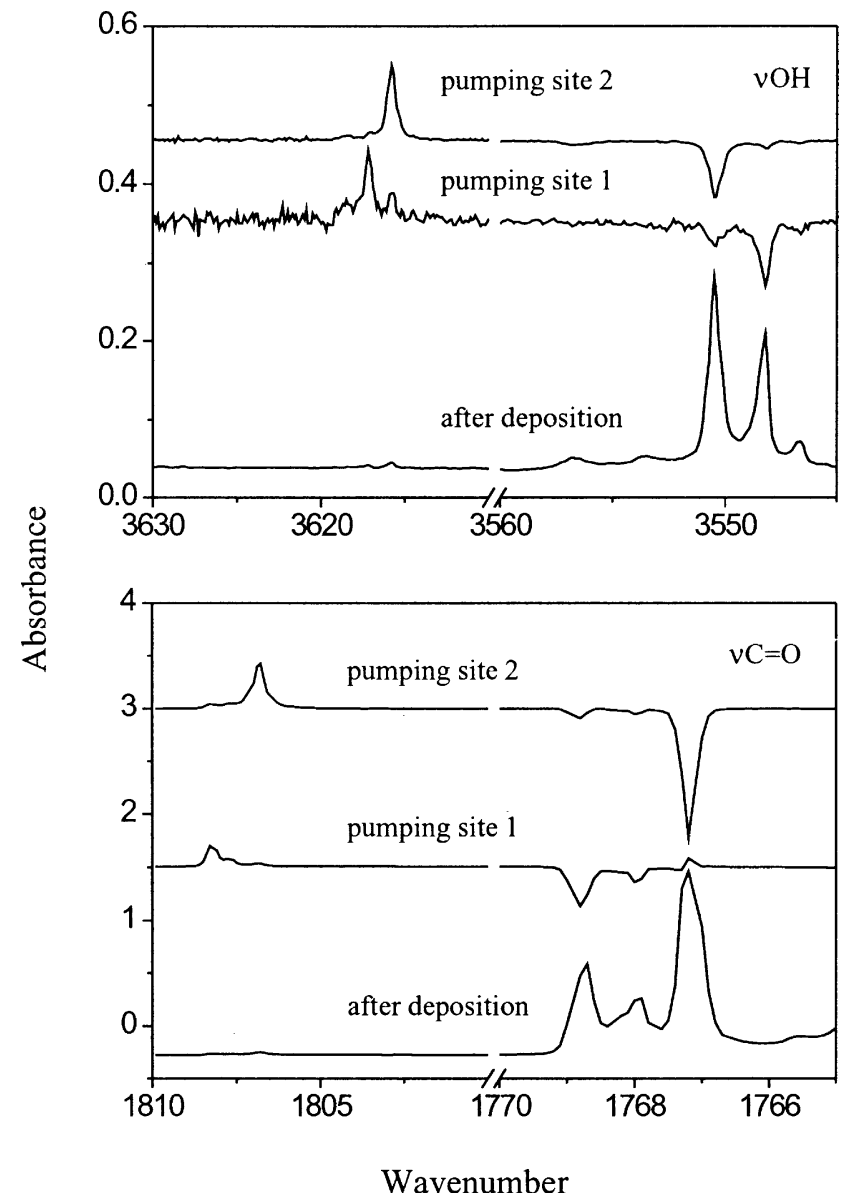

Fig. 2. Fragments of the mid-infrared spectra of $\mathrm{HCOOH}$ in solid Ar at $8 \mathrm{~K}$. The as-deposited samples contain the trans conformer (lower trace). Pumping of site 1 and site 2 of trans- $\mathrm{HCOOH}$ gives rise to the cis conformer as presented by the difference spectra (middle and upper traces).

properties of the guest molecule, which can split the absorption bands by coupling the vibrational transitions with libration motion of the molecule or by the equilibrium between different orientations of the molecule in the same site [21]. The presence of accidentally nearly degenerated sites besides the two main sites can also be responsible for the splitting. Since the vibrational bands for the two sites of the same conformer differ only by a few wavenumbers we will limit the following discussion to the assignment of the vibrational bands originating from the molecules isolated in site 2 .

Generally, for a carboxylic group displaying an $\mathrm{O}=\mathrm{C}-\mathrm{O}-\mathrm{H}$ dihedral angle of $180^{\circ}$ the $\mathrm{O}-\mathrm{H}$ and $\mathrm{C}=\mathrm{O}$ stretching vibrations occur at higher wavenumbers $\left(\mathrm{vOH} \approx 3616\right.$ and $\mathrm{vC}=\mathrm{O} \approx 1807 \mathrm{~cm}^{-1}$ for $\left.c i s-\mathrm{HCOOH}\right)$ than in the $0^{\circ}$ dihedral angle arrangement $(\mathrm{vOH} \approx 3550$ and $v \mathrm{C}=\mathrm{O} \approx 1768 \mathrm{~cm}^{-1}$ for trans-HCOOH). This is due to the different degree of the $[\mathrm{O}=\mathrm{C}-\mathrm{O}-\mathrm{H} \leftrightarrow$ $\left.\mathrm{O}^{-}-\mathrm{C}=\mathrm{O}^{+}-\mathrm{H}\right]$ mesomerism in the two conformations, which appears to be slightly less efficient in the higher energy cis configuration. This leads to a shortening of 


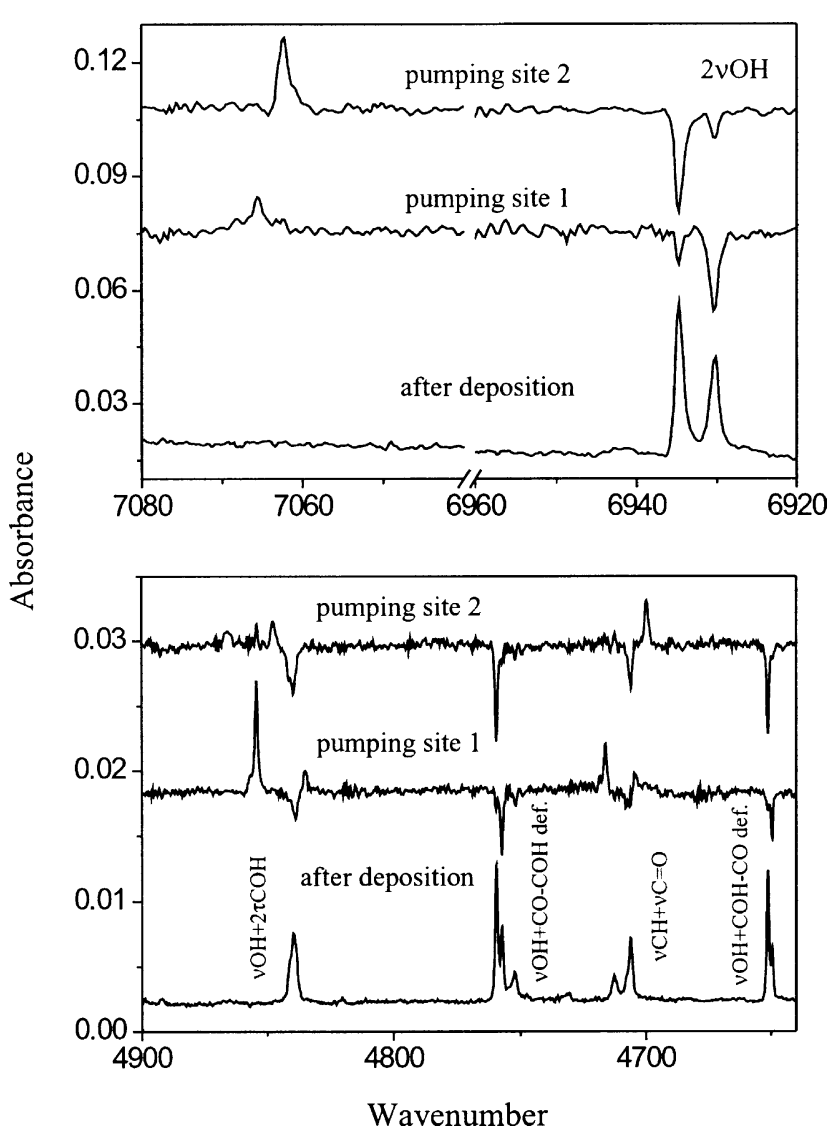

Fig. 3. Fragments of near-infrared spectra of $\mathrm{HCOOH}$ in solid $\mathrm{Ar}$ at $8 \mathrm{~K}$. The as-deposited samples contain the trans conformer (lower trace). Pumping of site 1 and site 2 of trans- $\mathrm{HCOOH}$ gives rise to the cis conformer as presented by the difference spectra (middle and upper traces).

the $\mathrm{C}=\mathrm{O}$ and $\mathrm{O}-\mathrm{H}$ bond distances and a lengthening of the $\mathrm{C}-\mathrm{O}$ bond distance, as well as the decrease of the OCO angle in the cis configuration when compared to the trans form [15,30,31]. The structural differences arising from the mesomerism do not have a counterpart on the $\mathrm{C}-\mathrm{O}$ stretching mode $(\mathrm{vC}-\mathrm{O})$ because it is generally a very mixed vibration. The observed $\mathrm{vOH}$ and $v \mathrm{C}=\mathrm{O}$ frequencies for both conformers of $\mathrm{HCOOH}$ are reproduced by the anharmonic calculations with an accuracy better than $1 \%$.

The $\mathrm{C}-\mathrm{H}$ rocking fundamental $(\gamma \mathrm{CH})$ of trans$\mathrm{HCOOH}$ appears as a weak band at $1381.0 \mathrm{~cm}^{-1}$, in good agreement with the calculations $\left(1388.7 \mathrm{~cm}^{-1}\right)$. For cis- $\mathrm{HCOOH}$ the weak band observed at $1391.8 \mathrm{~cm}^{-1}$ is assigned to the $\gamma \mathrm{CH}$ mode in site 2 while the corresponding mode for site 1 could not be detected. The weak band reported in [17] in this region $\left(1396 \mathrm{~cm}^{-1}\right)$ was not observed in the present experiments.

A Fermi resonance doublet was observed for trans$\mathrm{HCOOH}$ at 1305.7 and $1215.8 \mathrm{~cm}^{-1}$ involving the $\mathrm{CO}-$ $\mathrm{COH}$ deformation mode ( $\mathrm{CO}-\mathrm{COH}$ def.) and the first overtone of the $\mathrm{COH}$ torsion $(2 \tau \mathrm{COH})$. This resonance is well known and it has been considered to be responsible for the apparent shift of $2 \tau \mathrm{COH}$ towards higher wavenumbers in trans-HCOOH [8,10,11]. Simultaneously, the $\mathrm{CO}-\mathrm{COH}$ deformation in this conformer is observed at lower wavenumbers when compared with the cis form (although it was predicted by the calculations at higher wavenumbers). In the cis conformer, the $\tau \mathrm{COH}$ overtone is $270 \mathrm{~cm}^{-1}$ below the $\mathrm{CO}-\mathrm{COH}$ deformation mode $\left(\approx 980 \mathrm{~cm}^{-1}\right)$ and there is no analogous Fermi resonance involving these two modes.

A number of overtone and combination bands can be seen in the mid-IR region. The first overtone of the $\mathrm{vC}=\mathrm{O}$ vibration $(2 \mathrm{vC}=\mathrm{O})$ of $c i s-\mathrm{HCOOH}$, predicted by the anharmonic calculations at $3570.9 \mathrm{~cm}^{-1}$, was detected at $3595.4 \mathrm{~cm}^{-1}$. Both conformers of $\mathrm{HCOOH}$ exhibit a weak combination band appearing at slightly lower energies from the $\mathrm{CH}$ stretching fundamental. The observed band of the trans conformer (ca. $2865.6 \mathrm{~cm}^{-1}$ ) is assigned to the $v \mathrm{C}=\mathrm{O}+\mathrm{COH}-\mathrm{CO}$ def. combination in agreement with [14]. On the other hand, the observed band for cis (ca. $2753.4 \mathrm{~cm}^{-1}$ ) is tentatively assigned to the $v \mathrm{C}=\mathrm{O}+2 \tau \mathrm{COH}$ combination mode. The first overtone of the $\gamma \mathrm{CH}$ mode of the cis conformer could also be expected to give rise to a band in this region, but the assignment of the $2753.4 \mathrm{~cm}^{-1}$ band to this vibration can be ruled out because this band is more intense than the $\gamma \mathrm{CH}$ fundamental. On the other hand, for cis$\mathrm{HCOOH}$ the $v \mathrm{C}=\mathrm{O}$ is the most intense band and the $2 \tau \mathrm{COH}$ is one order of magnitude higher in intensity than the $\gamma \mathrm{CH}$ fundamental.

The band observed for trans- $\mathrm{HCOOH}$ at $2397.1 \mathrm{~cm}^{-1}$ is assigned to the $v \mathrm{C}=\mathrm{O}+\tau \mathrm{COH}$ combination mode. In the gas phase spectrum, two bands were detected in a $50 \mathrm{~cm}^{-1}$ interval region centered at this value [14]; the bands were assigned to the first overtone of the $\mathrm{CO}$ $\mathrm{COH}$ def. mode $\left(\approx 2400 \mathrm{~cm}^{-1}\right)$ and the combination of the carbonyl stretching with the $\mathrm{O}=\mathrm{C}-\mathrm{O}$ bending $\left(\mathrm{vC}=\mathrm{O}+\delta \mathrm{OCO} \approx 2376 \mathrm{~cm}^{-1}\right)$. In [14], the assignment of the $\mathrm{CO}-\mathrm{COH}$ def. overtone was made without taking into account the shift induced by the involvement of the fundamental in the Fermi resonance interaction mentioned above. For the unperturbed vibrational level we can expect this overtone to occur well above $2400 \mathrm{~cm}^{-1}$. Therefore, we reject the assignment of the $2397.1 \mathrm{~cm}^{-1}$ band to the $\mathrm{CO}-\mathrm{COH}$ def. overtone. Next, we consider the possible assignment of this band to the $v \mathrm{C}=\mathrm{O}+\delta \mathrm{OCO}$ mode. It can be approximated that the gas-to-matrix shift of the combination mode roughly follows the arithmetic sum of the gas-to-matrix shift of the two fundamentals involved $(\Delta v \mathrm{C}=\mathrm{O}=-9.6$ and $\left.\Delta \delta \mathrm{OCO}=+3.3 \mathrm{~cm}^{-1}\right)$. Then the $\mathrm{vC}=\mathrm{O}+\delta \mathrm{OCO}$ combination is expected to lie in the matrix spectrum at ca. $20 \mathrm{~cm}^{-1}$ below the observed frequency. The $\mathrm{vC}=\mathrm{O}+$ $\tau \mathrm{COH}$ combination mode is expected to lie at higher wavenumbers than the $\mathrm{vC}=\mathrm{O}+\delta \mathrm{OCO}$ mode and therefore closer to the observed value in the matrix 
Table 1

Observed vibrational frequencies $\left(\mathrm{cm}^{-1}\right)$ in the mid-IR for the two predominant sites of trans- and cis-HCOOH/DCOOH isolated in Ar at $8 \mathrm{~K}$ and calculated anharmonic vibrational frequencies (CC-VSCF) for the corresponding molecules in the gas phase

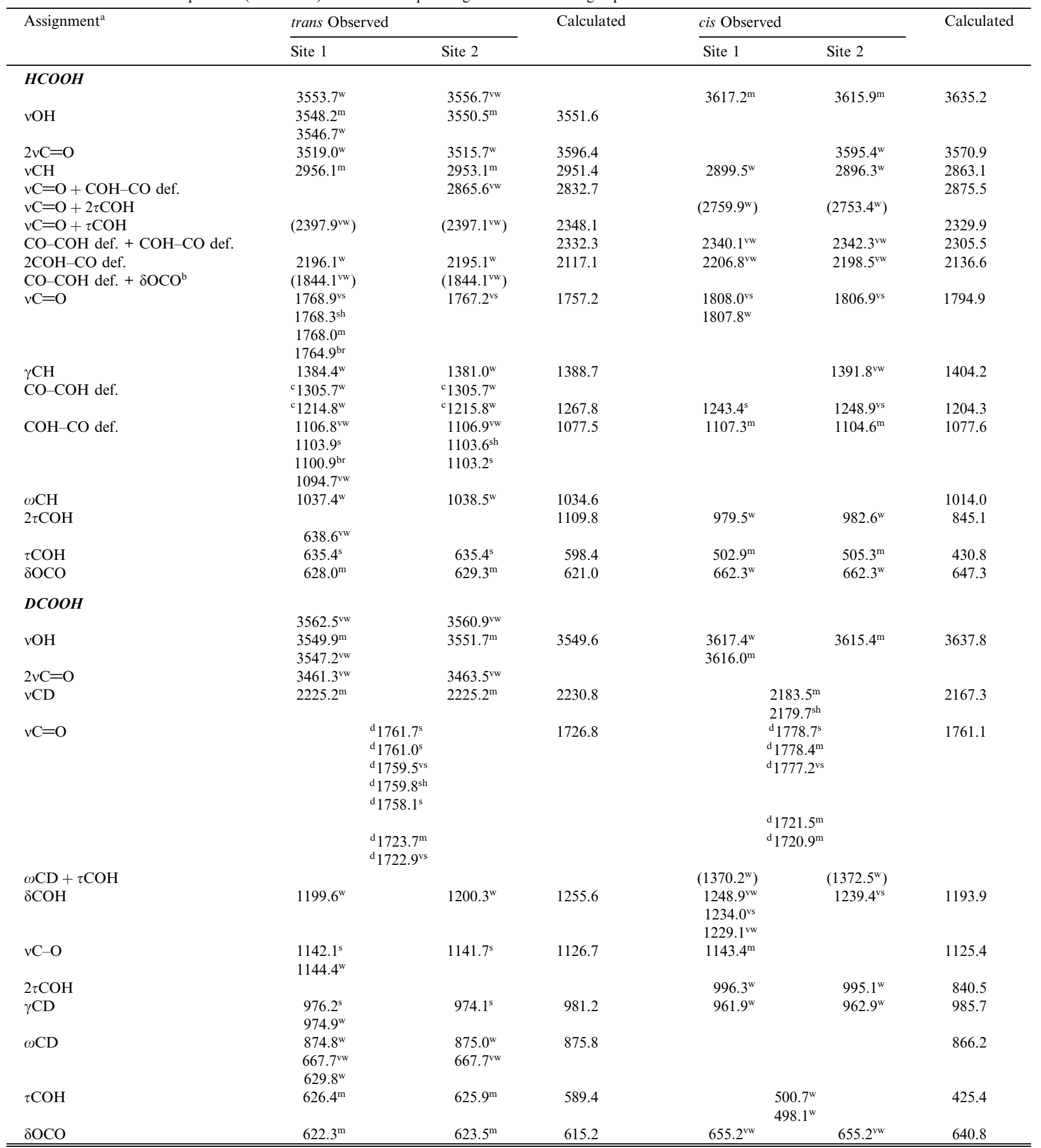

Qualitative information on intensities is given as superscript: vs, very strong; s, strong; m, medium; w, weak; vw, very weak; sh, shoulder; br, broad.

${ }^{a}$ According to [11]: $v$, stretching; $\delta$, bending; $\gamma$, rocking; $\omega$, wagging, def., deformation.

${ }^{\mathrm{b}}$ According to [14].

${ }^{\mathrm{c}}$ Components of a Fermi resonance doublet between the first overtone of $\tau \mathrm{COH}$ and the $\mathrm{CO}-\mathrm{COH}$ def. observed only for trans- $\mathrm{HCOOH}$

${ }^{\mathrm{d}}$ Components of a Fermi resonance doublet between the first overtone of the $\omega \mathrm{CD}$ and $v \mathrm{C}=\mathrm{O}$ modes.

Frequency values centered between site 1 and site 2 columns could not be assigned to a specific site due to lack of site selective data. Values in parentheses are tentatively assigned. An explanation about the assignment of several bands to the same mode in the site-selective spectra is given in the text. 
Table 2

Observed vibrational frequencies $\left(\mathrm{cm}^{-1}\right)$ in the near-IR for the two predominant sites of trans- and cis-HCOOH isolated in Ar at $8 \mathrm{~K}$ and calculated anharmonic vibrational frequencies (CC-VSCF) for the corresponding molecules in gas phase

\begin{tabular}{|c|c|c|c|c|c|c|c|c|}
\hline \multirow[t]{2}{*}{ Assignment } & \multicolumn{3}{|c|}{ trans-HCOOH } & \multirow[t]{2}{*}{ Gas phase $^{\mathrm{a}}$} & \multirow[t]{2}{*}{ Calc. } & \multicolumn{2}{|c|}{ cis-HCOOH } & \multirow[t]{2}{*}{ Calc. } \\
\hline & Ar site 1 & & Ar site 2 & & & Ar site 1 & Ar site 2 & \\
\hline $2 v \mathrm{OH}$ & $6930.3^{\mathrm{s}}$ & & $6934.8^{\mathrm{s}}$ & 6968 & 6943.7 & $7062.3^{\mathrm{s}}$ & $7065.7^{\mathrm{m}}$ & 7053.8 \\
\hline $2 v \mathrm{CH}+\omega \mathrm{CH}$ & & & & 6773 & & & & \\
\hline$v \mathrm{OH}+v \mathrm{CH}$ & & & & 6507 & 6431.0 & & & 6425.6 \\
\hline$v \mathrm{CH}+2 v \mathrm{C}=\mathrm{O}$ & \multicolumn{3}{|c|}{$6411.2^{\mathrm{vw}}$} & 6440 & & & & \\
\hline \multicolumn{9}{|c|}{$6407.0^{\mathrm{vw}}$} \\
\hline $2 v \mathrm{CH}$ & \multirow{2}{*}{\multicolumn{3}{|c|}{$\begin{array}{l}5803.0^{\mathrm{vw}} \\
5797.3^{\mathrm{vw}}\end{array}$}} & 5775 & 5788.3 & & & 5604.0 \\
\hline & & & & & & & & \\
\hline$v \mathrm{CH}+2 \gamma \mathrm{CH}$ & \multicolumn{3}{|c|}{$5797.3^{\mathrm{vw}}$} & 5592 & & & & \\
\hline$v \mathrm{OH}+v \mathrm{C}=\mathrm{O}$ & $5316.4^{\mathrm{m}}$ & & $5317.2^{\mathrm{m}}$ & 5343 & 5236.2 & & & 5347.2 \\
\hline \multirow[t]{2}{*}{$v \mathrm{OH}+\gamma \mathrm{CH}$} & \multirow{2}{*}{\multicolumn{2}{|c|}{$4928.7^{\mathrm{m}}$}} & $4926.1^{\mathrm{w}}$ & 4942 & 4863.5 & & & 4960.1 \\
\hline & & & $4841.2^{\mathrm{sh}}$ & & & & & \\
\hline$v \mathrm{OH}+2 \tau \mathrm{COH}^{\mathrm{b}}$ & $\left(4838.7^{\mathrm{m}}\right)$ & & $\left(4839.8^{\mathrm{m}}\right)$ & 4857 & & & & \\
\hline$v \mathrm{OH}+\mathrm{CO}-\mathrm{COH}$ def. $^{b}$ & $\left(4757.2^{\mathrm{m}}\right)$ & & $\left(4759.4^{\mathrm{m}}\right)$ & 4780 & 4686.1 & $4847.7^{\mathrm{m}}$ & $4854.4^{\mathrm{s}}$ & 4704.8 \\
\hline $2 v \mathrm{C}=\mathrm{O}+\mathrm{CO}-\mathrm{COH}$ def. & & & $\left(4752.2^{\mathrm{br}}\right)$ & & & & & \\
\hline$?$ & \multicolumn{3}{|c|}{4712.0} & & & & & \\
\hline$v \mathrm{CH}+v \mathrm{C}=\mathrm{O}$ & $4707.0^{\mathrm{vw}}$ & & $4706.0^{\mathrm{m}}$ & 4708 & 4708.3 & $4704.0^{\mathrm{w}}$ & $4700.0^{\mathrm{m}}$ & 4666.2 \\
\hline $\mathrm{vOH}+\mathrm{COH}-\mathrm{CO}$ def. & $4649.6^{\mathrm{m}}$ & & $4651.4^{\mathrm{m}}$ & 4670 & 4534.7 & $4716.2^{\mathrm{m}}$ & $4712.5^{\mathrm{w}}$ & 4622.6 \\
\hline$v \mathrm{OH}+\omega \mathrm{CH}$ & & & & 4600 & 4517.6 & & & 4576.6 \\
\hline $2 \gamma \mathrm{CH}+v \mathrm{C}=\mathrm{O}$ & \multicolumn{3}{|c|}{$4510.0^{\mathrm{vw}}$} & 4515 & & & $4553.4^{\mathrm{vw}}$ & \\
\hline$v \mathrm{CH}+\gamma \mathrm{CH}$ & \multirow{2}{*}{\multicolumn{3}{|c|}{$\begin{array}{c}4317.0^{\mathrm{w}} \\
\left(4270.4^{\mathrm{w}}\right)\end{array}$}} & 4300 & 4287.4 & & & 4219.3 \\
\hline $\mathrm{vC}=\mathrm{O}+2 \mathrm{CO}-\mathrm{COH}$ def. & & & & & & & & \\
\hline $\mathrm{vCH}+2 \tau \mathrm{COH}^{\mathrm{b}}$ & $\left(4254.2^{w}\right)$ & & $\left(4252.0^{w}\right)$ & 4242 & & & & \\
\hline$v \mathrm{OH}+\tau \mathrm{COH}$ & $\left(4183.6^{\mathrm{m}}\right)$ & & $\left(4185.2^{\mathrm{m}}\right)$ & 4209 & 4102.2 & $\left(4110.0^{\mathrm{vw}}\right)$ & $\left(4111.5^{\mathrm{vw}}\right)$ & 4130.2 \\
\hline$v \mathrm{CH}+\mathrm{CO}-\mathrm{COH}$ def. $^{b}$ & $\left(4171.8^{w}\right)$ & & $\left(4175.1^{w}\right)$ & & 4214.4 & & & 4098.7 \\
\hline$v \mathrm{OH}+\delta \mathrm{OCO}$ & \multirow{2}{*}{\multicolumn{3}{|c|}{$\begin{array}{c}\left(4167.4^{\mathrm{vw}}\right) \\
4157.7^{\mathrm{vw}}\end{array}$}} & 4192 & 4085.8 & $4277.3^{\mathrm{vw}}$ & $4275.9^{\mathrm{vw}}$ & 4195.8 \\
\hline$?$ & & & & & & & & \\
\hline$v \mathrm{CH}+\mathrm{COH}-\mathrm{CO}$ def. & $4059.7^{\mathrm{w}}$ & & $4055.3^{\mathrm{w}}$ & 4043 & 4026.6 & & & \\
\hline
\end{tabular}

Qualitative information on intensities is given as superscript: vs- very strong; s, strong; m- medium; w, weak; vw, very weak; sh, shoulder; br, broad. Frequencies in parentheses correspond to tentative assignments.

${ }^{a}$ From [14]. $v$, stretching; $\delta$, bending; $\gamma$, rocking; $\omega$, waging; def., deformation.

${ }^{\mathrm{b}}$ Ascribed as components of a Fermi resonance doublet between the combination modes $v \mathrm{OH}(v \mathrm{CH})+2 \tau \mathrm{COH}$ and $v \mathrm{OH}(v \mathrm{CH})+\mathrm{CO}-\mathrm{COH}$ def. of the trans conformer.

making this assignment most plausible. No bands were observed in the matrix spectrum that could be ascribed to the $2 \mathrm{CO}-\mathrm{COH}$ def. or $\mathrm{vC}=\mathrm{O}+\delta \mathrm{OCO}$ modes.

The $\mathrm{CO}-\mathrm{COH}$ def. + $\mathrm{COH}-\mathrm{CO}$ def. combination band was observed for cis- $\mathrm{HCOOH}$ at $2342.3 \mathrm{~cm}^{-1}$ and calculated at $2305.5 \mathrm{~cm}^{-1}$. The corresponding mode was not detected for the trans conformer, in agreement with its predicted lower intensity (four times lower than in the cis conformer). The very weak band observed for cis$\mathrm{HCOOH}$ at $2198.5 \mathrm{~cm}^{-1}$ is ascribed to the overtone of the $\mathrm{COH}-\mathrm{CO}$ def. mode, which in the trans conformer gives rise to the band at $2195.1 \mathrm{~cm}^{-1}$ [11].

Following the gas phase assignment [14], the very weak band observed for trans- $\mathrm{HCOOH}$ at $1844.1 \mathrm{~cm}^{-1}$ is tentatively ascribed to the $\mathrm{CO}-\mathrm{COH}$ def. $+\delta \mathrm{OCO}$ combination. However, its assignment to the $\mathrm{CO}-\mathrm{COH}$ def. $+\tau \mathrm{COH}$ mode is also possible. Indeed, for trans$\mathrm{HCOOH}$ it is difficult to distinguish the combination modes involving $\delta \mathrm{OCO}$ or $\tau \mathrm{COH}$ because these two fundamentals appear at similar frequencies. Note that in the case of the cis conformer the $\tau \mathrm{COH}$ and $\delta \mathrm{OCO}$ fundamentals are separated by approximately $155 \mathrm{~cm}^{-1}$, which allows us to reliably distinguish the combination modes involving each vibration.

For $\mathrm{DCOOH}$ the $\mathrm{C}=\mathrm{O}$ stretching mode participates in a very strong Fermi resonance with the first overtone of the $\mathrm{CD}$ wagging mode $(2 \omega \mathrm{CD})$ in both isomers (see Table 1) [10,11]. Therefore, the previously discussed dependency of the $v \mathrm{C}=\mathrm{O}$ on the conformation is not observed for $\mathrm{DCOOH}$, with both conformers giving rise to bands at similar frequency values. The $2 \omega \mathrm{CD}$ is predicted to be more than two orders of magnitude lower in intensity than the $\mathrm{vC}=\mathrm{O}$ for both conformers of DCOOH. However, the observed ratio of intensities $(2 \omega \mathrm{CD}: v \mathrm{C}=\mathrm{O})$ is roughly $1: 2$ and $1: 5$ for trans- and cis-DCOOH, respectively, due to the involvement of the two vibrations in the Fermi resonance interaction. Despite the larger intensity ratio of the Fermi doublet for trans-DCOOH, the observed frequency splitting between the components is larger for cis-DCOOH (ca. 57 and $37 \mathrm{~cm}^{-1}$ in trans-DCOOH). Accordingly, the Fermi resonance coupling coefficients $(W)$, obtained from a standard perturbative analysis [32], for cis- and trans$\mathrm{DCOOH}$ are ca. 21 and $18 \mathrm{~cm}^{-1}$, respectively, also 
Table 3

Observed near-IR active vibrational frequencies $\left(\mathrm{cm}^{-1}\right)$ of the trans conformer of DCOOH, HCOOD and DCOOD isolated in Ar at 8 K $\mathrm{K}^{\mathrm{a}}$ and calculated anharmonic vibrational frequencies (CC-VSCF) for the corresponding molecules in gas phase

\begin{tabular}{|c|c|c|c|c|c|c|c|c|c|c|c|}
\hline \multicolumn{4}{|l|}{$\mathrm{DCOOH}$} & \multicolumn{4}{|l|}{ HCOOD } & \multicolumn{4}{|l|}{ DCOOD } \\
\hline Assignment & Ar & $\begin{array}{l}\text { Gas } \\
\text { phase }^{\mathrm{b}}\end{array}$ & Calc. & Assignment & $\mathrm{Ar}$ & $\begin{array}{l}\text { Gas } \\
\text { phase }^{b}\end{array}$ & Calc. & Assignment & $\mathrm{Ar}$ & $\begin{array}{l}\text { Gas } \\
\text { phase }^{\mathrm{b}}\end{array}$ & Calc. \\
\hline $2 v \mathrm{OH}$ & $\begin{array}{l}6937.4 \\
6933.3\end{array}$ & 6975 & 6939.4 & $2 v \mathrm{OD}$ & $\begin{array}{l}5152.9 \\
5149.7\end{array}$ & 5181 & 5163.6 & $2 v O D$ & $\begin{array}{l}5152.9 \\
5149.7\end{array}$ & 5181 & 5169.1 \\
\hline$v \mathrm{OH}+v \mathrm{CD}$ & 5773.2 & & 5708.9 & $v \mathrm{OH}+v \mathrm{CD}$ & & & 5547.2 & $v \mathrm{OD}+v \mathrm{CD}$ & & & 4823.5 \\
\hline $2 v \mathrm{CD}$ & 4401.2 & $\approx 4360^{\mathrm{e}}$ & 4400.8 & $2 v \mathrm{CH}$ & & & 5791.3 & $2 v \mathrm{CD}$ & & & 4398.7 \\
\hline$v \mathrm{OH}+2 \omega \mathrm{CD}^{\mathrm{c}}$ & $(5312.0)$ & & & $v \mathrm{OD}+v \mathrm{C}=\mathrm{O}$ & 4382.2 & 4404 & 4345.8 & $v \mathrm{OD}+v \mathrm{C}=\mathrm{O}$ & & & 4318.3 \\
\hline$v \mathrm{OH}+v \mathrm{C}=\mathrm{O}^{\mathrm{c}}$ & $(5273.9)$ & & 5205.5 & & 4380.0 & & & & & & \\
\hline$v \mathrm{OH}+2 \tau \mathrm{COH}^{\mathrm{d}}$ & $\begin{array}{l}(4835.1) \\
(4825.3)\end{array}$ & 4850 & & & & & & & & & \\
\hline$v \mathrm{OH}+\delta \mathrm{COH}^{\mathrm{d}}$ & $\begin{array}{l}(4743.3) \\
(4740.9)\end{array}$ & 4781 & 4649.5 & & & & & & & & \\
\hline $\begin{array}{l}\nu \mathrm{OH}+\gamma \mathrm{CD} \\
v \mathrm{OH}+\omega \mathrm{CD}\end{array}$ & & & $\begin{array}{l}4451.5 \\
4356.5\end{array}$ & & & & & & & & \\
\hline & & & & $v \mathrm{CH}+\gamma \mathrm{CH}$ & $\cdot$ & & 4275.8 & & & & \\
\hline$v C D+2 \omega C^{c}$ & (3974.3) & 3980 & & $v \mathrm{CH}+v \mathrm{C}=\mathrm{O}$ & 4723.7 & 4736 & 4704.3 & $v \mathrm{CD}+v \mathrm{C}=\mathrm{O}$ & 3987.1 & 3981 & 3949.2 \\
\hline$v C D+v C=O^{c}$ & $(3937.3)$ & & 3953.4 & & 4721.1 & 4702 & & & & & \\
\hline$v \mathrm{OH}+v \mathrm{CO}$ & $\begin{array}{l}4693.2 \\
4691.7\end{array}$ & 4701 & 4593.1 & $v \mathrm{CH}+v \mathrm{CO}$ & $\begin{array}{l}4142.6 \\
4141.2\end{array}$ & $\begin{array}{l}4144 \\
4115\end{array}$ & 4114.4 & & & & \\
\hline$v \mathrm{OH}+\tau \mathrm{COH}$ & $\begin{array}{l}4175.4 \\
4173.3\end{array}$ & & 4098.6 & $v \mathrm{CH}+\omega \mathrm{CH}$ & $\begin{array}{l}3990.2 \\
3988.2\end{array}$ & & 3926.9 & & & & \\
\hline$v \mathrm{OH}+\delta \mathrm{OCO}$ & 4170.2 & 4201 & 4076.2 & & & & & & & & \\
\hline & 4166.7 & & & $\begin{array}{l}v \mathrm{CH}+2 \tau \mathrm{COD} \\
v \mathrm{CH}+\delta \mathrm{COD}\end{array}$ & $\begin{array}{l}3946.2 \\
.\end{array}$ & & 3923.4 & & & & \\
\hline
\end{tabular}

${ }^{\mathrm{a}}$ The majority of the modes appear site-splitted.

${ }^{\mathrm{b}}$ From [13].

${ }^{c}$ Components of a Fermi resonance doublet between the combination modes $v \mathrm{OH}(v \mathrm{CD})+2 \omega \mathrm{CD}$ and $v \mathrm{OH}(v \mathrm{CD})+v \mathrm{C}=\mathrm{O}$.

${ }^{\mathrm{d}}$ Fermi resonance doublet between the combination modes $\mathrm{vOH}+2 \tau \mathrm{COH}$ and $v \mathrm{OH}+\delta \mathrm{COH}$.

${ }^{\mathrm{e}}$ Band center of the observed doublet ascribed to rotational structure. $v$, stretching; $\delta$, bending; $\gamma$, rocking; $\omega$, wagging; def., deformation.

Frequencies in parentheses correspond to tentative assignments.

pointing to a stronger coupling between the $\mathrm{v} C=\mathrm{O}$ and the $2 \omega \mathrm{CD}$ in the cis form.

It has been suggested that the $\mathrm{COH}$ bending $(\mathrm{COOH})$ in trans-DCOOH is also involved in a Fermi interaction together with the $2 \tau \mathrm{COH}$ mode (the $\tau \mathrm{COH}$ fundamental appears at $\approx 626 \mathrm{~cm}^{-1}$ ) [11]. This is supported by our observation that the $\delta \mathrm{COH}$ absorption band in cis$\mathrm{DCOOH}$ is much higher in energy $\left(1239.4 \mathrm{~cm}^{-1}\right)$ than the corresponding band for trans-DCOOH (1200.3 $\mathrm{cm}^{-1}$ ), although the calculations predict the opposite trend (see Table 1). The Fermi resonance in trans$\mathrm{DCOOH}$ shifts the $\delta \mathrm{COH}$ level down. In cis-DCOOH the overtone of the $\tau \mathrm{COH}$ mode is observed at $995.1 \mathrm{~cm}^{-1}$, which is too low to enable its involvement in a Fermi resonance with the $\delta \mathrm{COH}$ mode.

The $\tau \mathrm{COH}$ fundamental mode is observed at $\approx 500 \mathrm{~cm}^{-1}$ for the cis conformer in both $\mathrm{HCOOH}$ and DCOOH. This vibration is shifted $\approx 130 \mathrm{~cm}^{-1}$ towards lower wavenumbers when compared with the same vibration in the trans conformer (see Table 1). The repulsive interaction between the $\mathrm{C}=\mathrm{O}$ and $\mathrm{O}-\mathrm{H}$ bond dipoles resulting from their nearly parallel alignment and the steric repulsion between the hydrogen atoms lying on the same side of the $\mathrm{C}-\mathrm{O}$ bond in the cis configuration have been pointed out as the major factors responsible for the higher energy of the cis conformer when compared with the trans form [18]. Indeed, these effects partially destabilize the cis planar conformations of this molecule with respect to the non-planar conformations. Thus, it leads to a softer torsional energy profile around this conformer and decreases the force constant of the torsion.

\section{Near-IR region}

In this section, we analyze the near-IR (7900 $4000 \mathrm{~cm}^{-1}$ ) spectra of the two conformers of formic acid, the discussion being focused on site 2. The $\mathrm{OH}$ stretching absorption bands of trans-formic acid were used to promote the site-selective rotamerization process (Fig. 3). Table 2 presents the observed vibrational frequencies for both $\mathrm{HCOOH}$ conformers and the results of the anharmonic vibrational calculations. Table 3 collects the observed and calculated vibrational frequencies for trans-DCOOH, HCOOD, and DCOOD omitting site labeling.

The first $\mathrm{OH}$ stretching overtone of trans- $\mathrm{HCOOH}$ is observed at $6934.8 \mathrm{~cm}^{-1}$ and predicted by the calculations at $6943.7 \mathrm{~cm}^{-1}$, both of them being in good 
agreement with the existing gas phase data $\left(6968 \mathrm{~cm}^{-1}\right.$ [14]). For cis- $\mathrm{HCOOH}$ the same mode is predicted by the calculations at $7053.8 \mathrm{~cm}^{-1}$ and observed at $7065.7 \mathrm{~cm}^{-1}$. The experimentally determined anharmonicity constant for the $\mathrm{OH}$ stretching mode of cis$\mathrm{HCOOH}$ is ca. $-85 \mathrm{~cm}^{-1}$, which is very close to the values obtained for the trans conformer (ca. $-83 \mathrm{~cm}^{-1}$ and $-91 \mathrm{~cm}^{-1}$, matrix isolated and gas phase [14], respectively). The $\mathrm{vOH}+\mathrm{vCH}$ mode, observed in the gas phase for trans-HCOOH at $6507 \mathrm{~cm}^{-1}$, was not found in our matrix studies. For trans-DCOOH a band appearing at $5773.2 \mathrm{~cm}^{-1}$ is assigned to the $v \mathrm{OH}+v \mathrm{CD}$ mode (predicted by the CC-VSCF calculations at $\left.5708.9 \mathrm{~cm}^{-1}\right)$.

For trans-HCOOH, the medium intensity bands observed at 4839.8 and $4759.4 \mathrm{~cm}^{-1}$ are here ascribed to the $v \mathrm{OH}+2 \tau \mathrm{COH}$ and $v \mathrm{OH}+\mathrm{CO}-\mathrm{COH}$ def. combination modes. Considering the observed fundamental vibrations, it is reasonable to assign the higher frequency band to a combination mode involving the $\mathrm{vOH}$ fundamental and the overtone of $\delta \mathrm{OCO}$ or $\tau \mathrm{COH}$. In both cases, the observed combination mode would be shifted up from the expected value (even without taking into account the anharmonicity). This could be explained by a Fermi resonance coupling with a mode laying at similar wavenumbers. As discussed earlier, in the mid-IR region the $2 \tau \mathrm{COH}$ and $\mathrm{CO}-\mathrm{COH}$ def. modes are coupled by Fermi resonance, and it is plausible that the combination mode of each of these vibrations with the same $\mathrm{vOH}$ fundamental is also perturbed in a similar way. In the gas phase [14], the band at $4857 \mathrm{~cm}^{-1}$ was tentatively assigned to the $\mathrm{VOH}+2 \tau \mathrm{COH}$ combination mode while the band at $4780 \mathrm{~cm}^{-1}$ was assigned to the $\mathrm{vOH}+\mathrm{CO}-\mathrm{COH}$ def. combination mode. In [14], the existence of the Fermi resonance coupling between the $2 \tau \mathrm{COH}$ and $\mathrm{CO}-\mathrm{COH}$ def. modes was ignored, and the perturbed vibrational levels were used to estimate the position of the combination modes. In cis- $\mathrm{HCOOH}$, only one band that can be ascribed to the $\mathrm{vOH}+$ $\mathrm{CO}-\mathrm{COH}$ def. is observed in the $4900-4700 \mathrm{~cm}^{-1}$ region $\left(4854.4 \mathrm{~cm}^{-1}\right)$. This is in agreement with the fact that the $v \mathrm{OH}+2 \tau \mathrm{COH}$ combination mode is expected to occur at significantly lower wavenumbers (in the 4600$4500 \mathrm{~cm}^{-1}$ region, see Table 1), therefore preventing its involvement in a Fermi resonance of the same type as that observed for trans-HCOOH.

The $c i s-\mathrm{HCOOH}$ absorption band at $4700.0 \mathrm{~cm}^{-1}$ is ascribed to the $\mathrm{vCH}+\mathrm{vC}=\mathrm{O}$ combination, observed for trans-HCOOH at $4706.0 \mathrm{~cm}^{-1}$ (see site 2 data in Table 2). The cis-band at $4712.5 \mathrm{~cm}^{-1}$ is assigned to the $\mathrm{vOH}+\mathrm{COH}-\mathrm{CO}$ def. combination, observed at a frequency ca. $60 \mathrm{~cm}^{-1}$ higher than that of the trans-conformer $\left(4651.4 \mathrm{~cm}^{-1}\right)$. The magnitudes of the coupling constants for these two modes seem to be reversed in cis$\mathrm{HCOOH}$ (coupling constant $x_{i j}=v_{i+j}-v_{i}-v_{j} \approx-3.2$ and $-8.0 \mathrm{~cm}^{-1}$ for $\mathrm{vCH}+v \mathrm{C}=\mathrm{O}$ and $\mathrm{vOH}+\mathrm{COH}-\mathrm{CO}$ def., respectively) when compared to trans- $\mathrm{HCOOH}$ $\left(x_{i j} \approx-14.3 \mathrm{~cm}^{-1}\right.$ and $-2.3 \mathrm{~cm}^{-1}$, respectively). However, the alternative assignment of the lower frequency band to the $\mathrm{vCH}+\mathrm{vC}=\mathrm{O}$ would result in a positive coupling constant for the $v \mathrm{CH}+v \mathrm{C}=\mathrm{O}$ mode, which seems unlikely.

In the $4200-4150 \mathrm{~cm}^{-1}$ region few bands are observed for both isomers that are tentatively assigned. Three site-splitted bands are observed for trans- $\mathrm{HCOOH}$, ascribed to the $v \mathrm{OH}+\tau \mathrm{COH}, v \mathrm{OH}+\delta \mathrm{OCO}$, and $\nu \mathrm{CH}+$ $\mathrm{CO}-\mathrm{COH}$ def. combination modes (see Table 2). The assignment of these bands follows that made previously in [14]. A very weak band observed at $4111.5 \mathrm{~cm}^{-1}$ for $c i s-\mathrm{HCOOH}$ can be due either to the $v \mathrm{OH}+\tau \mathrm{COH}$ combination mode (the sum of the fundamentals gives ca. $4120 \mathrm{~cm}^{-1}$ ) or the $v \mathrm{CH}+\mathrm{CO}-\mathrm{COH}$ def. vibration (the sum of the fundamentals gives ca. $\left.4144 \mathrm{~cm}^{-1}\right)$. The $\mathrm{VOH}+\delta \mathrm{OCO}$ combination band is observed for cis-HCOOH at ca. $4276 \mathrm{~cm}^{-1}$ as a weakly coupled mode (the sum of the fundamentals is ca. $4278 \mathrm{~cm}^{-1}$ ). As already mentioned, the difference between the observed frequencies for the $\tau \mathrm{COH}$ and $\delta \mathrm{OCO}$ fundamentals in $c i s-\mathrm{HCOOH}$ allows us to reliably separate the combination modes involving each one of these vibrations.

For trans-DCOOH the bands observed at $\approx 4830$ and $4740 \mathrm{~cm}^{-1}$ are tentatively assigned to a Fermi resonance doublet involving $\mathrm{vOH}+2 \tau \mathrm{COH}$ and $v \mathrm{OH}+\delta \mathrm{COH}$, in a similar way to what was found for trans- $\mathrm{HCOOH}$. Another Fermi resonance doublet was observed in the trans-DCOOH spectrum coupling the $v \mathrm{OH}+2 \omega \mathrm{CD}$ with the $\mathrm{vOH}+v \mathrm{C}=\mathrm{O}$ (see Table 3). The splitting between this Fermi resonance doublet is identical to that observed in the mid-IR for the very strong Fermi resonance doublet involving the $2 \omega \mathrm{CD}$ and $\mathrm{vC}=\mathrm{O}$ modes (ca. $37 \mathrm{~cm}^{-1}$ ). The unperturbed frequencies of the $2 \omega \mathrm{CD}$ and $\mathrm{vC}=\mathrm{O}$ vibrations are estimated to be ca. 1746 and $1738 \mathrm{~cm}^{-1}$, respectively. The unperturbed $\mathrm{vOH}+2 \omega \mathrm{CD}$ and $\mathrm{vOH}+v \mathrm{C}=\mathrm{O}$ combination modes are expected at ca. 5297 and $5289 \mathrm{~cm}^{-1}$, respectively, using site averaged values and without taking into account the intermode coupling constant. By comparison of these values with the observed combination bands $\left(5312\right.$ and $\left.5274 \mathrm{~cm}^{-1}\right)$, we estimate a Fermi resonance induced shift relative to the unperturbed positions of $15 \mathrm{~cm}^{-1}$, exactly the same as that calculated for the mid-IR active Fermi doublet due to $v \mathrm{C}=\mathrm{O}$ and $2 \omega \mathrm{CD}$.

In Table 4, we present several observed and calculated (CC-VSCF) coupling and anharmonicity constants for cis- and trans-HCOOH together with the corresponding gas phase data [14]. By comparing the coupling constants obtained for trans- $\mathrm{HCOOH}$ isolated in argon with the gas phase data, we conclude that the cage potential affects significantly the guest intermode couplings. These changes in the coupling constants are in many cases of similar magnitude as the constants 
Table 4

Observed and CC-VSCF calculated anharmonicities and coupling constants ${ }^{\text {a }}$ for cis- $^{\text {and }}$ trans-HCOOH

\begin{tabular}{|c|c|c|c|c|c|c|c|}
\hline & \multicolumn{4}{|c|}{ trans-HCOOH } & \multicolumn{3}{|c|}{ cis-HCOOH } \\
\hline & Site 1 & Site 2 & Gas phase ${ }^{b}$ & Calc. & Site 1 & Site 2 & Calc. \\
\hline Combinations & \multicolumn{7}{|c|}{ Coupling constants $\left(x_{i j}, \mathrm{~cm}^{-1}\right)$} \\
\hline$v \mathrm{OH}+v \mathrm{C}=\mathrm{O}$ & -0.7 & -0.5 & -1.2 & -72.6 & & & -82.9 \\
\hline$v \mathrm{OH}+\gamma \mathrm{CH}$ & \multirow[t]{2}{*}{-3.9} & \multirow[t]{2}{*}{-5.4} & \multirow[t]{2}{*}{-3.6} & -76.8 & & & -79.3 \\
\hline$v \mathrm{OH}+\mathrm{CO}-\mathrm{COH}$ def. & & & & -133.3 & -12.9 & -10.4 & -134.7 \\
\hline$v \mathrm{OH}+\mathrm{COH}-\mathrm{CO}$ def. & \multirow[t]{2}{*}{-2.5} & \multirow[t]{2}{*}{-2.3} & \multirow{2}{*}{\multicolumn{2}{|c|}{$\begin{array}{l}-1.8 \\
-1.0\end{array}$}} & \multirow[t]{2}{*}{-8.3} & \multirow[t]{2}{*}{-8.0} & \multirow[t]{2}{*}{-90.2} \\
\hline$v \mathrm{OH}+\omega \mathrm{CH}$ & & & & & & & \\
\hline$v \mathrm{OH}+\tau \mathrm{COH}$ & $(0)$ & $(-0.7)$ & $(-2.2)$ & -47.8 & $(-10.1)$ & $(-9.7)$ & +64.2 \\
\hline$v \mathrm{OH}+\delta \mathrm{OCO}$ & \multicolumn{2}{|c|}{$(-15.5)$} & $(-4.7)$ & -86.8 & -2.2 & -2.3 & -86.7 \\
\hline$v \mathrm{CH}+v \mathrm{C}=\mathrm{O}$ & -18.0 & -14.3 & -5.4 & -0.3 & \multirow[t]{4}{*}{-3.5} & \multirow[t]{4}{*}{-3.2} & -8.2 \\
\hline$v \mathrm{CH}+\gamma \mathrm{CH}$ & -23.5 & -17.1 & -22.1 & -52.7 & & & -48.0 \\
\hline$v \mathrm{CH}+\mathrm{COH}-\mathrm{CO}$ def. & \multirow[t]{3}{*}{-0.3} & \multirow[t]{2}{*}{-1.0} & -1.8 & -2.3 & & & \multirow[t]{2}{*}{-7.7} \\
\hline$v \mathrm{CH}+\omega \mathrm{CH}$ & & & -5.7 & & & & \\
\hline$v \mathrm{C}=\mathrm{O}+\mathrm{COH}-\mathrm{CO}$ def. & & -4.8 & \multirow[t]{3}{*}{-2.6} & -2.0 & & & \multirow{3}{*}{$\begin{array}{r}-3.0 \\
-104.2 \\
-23.6\end{array}$} \\
\hline$v \mathrm{C}=\mathrm{O}+\tau \mathrm{COH}$ & \multirow[t]{2}{*}{$(-6.4)$} & \multirow[t]{2}{*}{$(-5.5)$} & & -7.5 & & & \\
\hline $\mathrm{CO}-\mathrm{COH}$ def. + $\mathrm{COH}-\mathrm{CO}$ def. & & & & -7.0 & -10.6 & -11.2 & \\
\hline Overtones & \multicolumn{7}{|c|}{ Anharmonicity constants $\left(x_{i j}, \mathrm{~cm}^{-1}\right)$} \\
\hline $2 \mathrm{vOH}$ & -83.1 & -83.1 & -91.2 & -79.8 & -86.1 & -83.1 & -108.3 \\
\hline $2 v \mathrm{CH}$ & \multicolumn{2}{|c|}{-53.1} & -52.4 & -57.3 & & & -61.1 \\
\hline $2 v \mathrm{C}=\mathrm{O}$ & -9.4 & -9.4 & -9.3 & -9.0 & & -9.2 & -9.5 \\
\hline $2 \mathrm{COH}-\mathrm{CO}$ def. & -5.9 & -5.7 & -6.6 & -19.0 & -3.9 & -5.4 & -9.3 \\
\hline $2 \tau \mathrm{COH}$ & & & & -43.5 & -13.2 & -14.0 & -8.3 \\
\hline
\end{tabular}

${ }^{\mathrm{a}} x_{i j}=\mathrm{v}_{i+j}-\mathrm{v}_{i}-\mathrm{v}_{j} ; x_{i i}=\left(2 \mathrm{v}_{i}-2 \cdot \mathrm{v}_{i}\right) / 2$.

${ }^{\mathrm{b}}$ Gas phase data was taken from [14].

Values in parentheses were calculated based on a tentative assignment. Values centered between site 1 and site 2 columns are average estimates for the two sites.

themselves. Moreover, changing of the matrix trapping site leads also to significant effects on the anharmonicity and intermode couplings (see, for example, the constants of either $v \mathrm{CH}+v \mathrm{C}=\mathrm{O}$ or $v \mathrm{CH}+\gamma \mathrm{CH}$ modes in Table 4). It can then be concluded that the local environment is an important factor to be considered in the processes involving intramolecular vibrational redistribution and relaxation in solid phase. The average difference between the constants estimated for both sites and the gas phase values is approximately the same in both conformers, which means that the local environment perturbs both conformers to a similar extent.

\section{Anharmonic calculations}

The equilibrium structures and harmonic vibrational properties of the conformers of formic acid are rather well reproduced at the MP2/6-311++G(2d,2p) level of theory employed previously in our studies of $\mathrm{HCOOH}$ $[27,28]$. The harmonic and anharmonic vibrational frequencies computed for trans- and cis- $\mathrm{HCOOH}$ are compared in Table 5. The anharmonic effects are most significant for the high-frequency modes, i.e. the $\mathrm{OH}$ and $\mathrm{CH}$ stretches, for which the anharmonic calculations reduce the obtained frequencies by $\approx 200 \mathrm{~cm}^{-1}$ from the harmonic values. The CC-VSCF calculations give a good reproduction of the experimentally observed positions for most of the fundamental frequencies. Only the skeletal deformation modes $(\mathrm{CO}-\mathrm{COH}$ def. and $\mathrm{COH}-\mathrm{CO}$ def.) and the torsional mode seem to be troublesome. For example, the CC-VSCF calculations predict the torsional mode to be $c a .40$ and $70 \mathrm{~cm}^{-1}$ below the experimental values of trans- and cis$\mathrm{HCOOH}$, respectively (see Table 5). The infrared intensities obtained both in the harmonic and anharmonic calculations are rather similar and both follow qualitatively the experimentally observed data.

The CC-VSCF calculations reveal a rather rich overtone and combination band spectrum for both conformers in qualitative accord with the experimentally observed spectra. However, the numerical agreement between the experimentally found vibrational frequencies and the CC-VSCF ones are not as good as in the case of the fundamental modes. For the first overtones of the $\mathrm{OH}$ and $\mathrm{CH}$ stretching modes, the calculations give reasonable estimates of the band positions. On the other hand, most of the combination bands and overtones involving one or several skeletal deformation modes seem to be a challenge for the CC-VSCF method. The results of the anharmonic CC-VSCF calculations are compared with the experimental data in Table 4 in the form of computed anharmonicity and coupling constants for the observed overtone and combination bands. The errors made in computing the fundamentals are reflected in the overtones and combination modes, 
Table 5

Harmonic and anharmonic vibrational frequencies $\left(\mathrm{cm}^{-1}\right)$ and infrared intensities (in parentheses) of trans- and cis-formic acid ${ }^{\text {a }}$

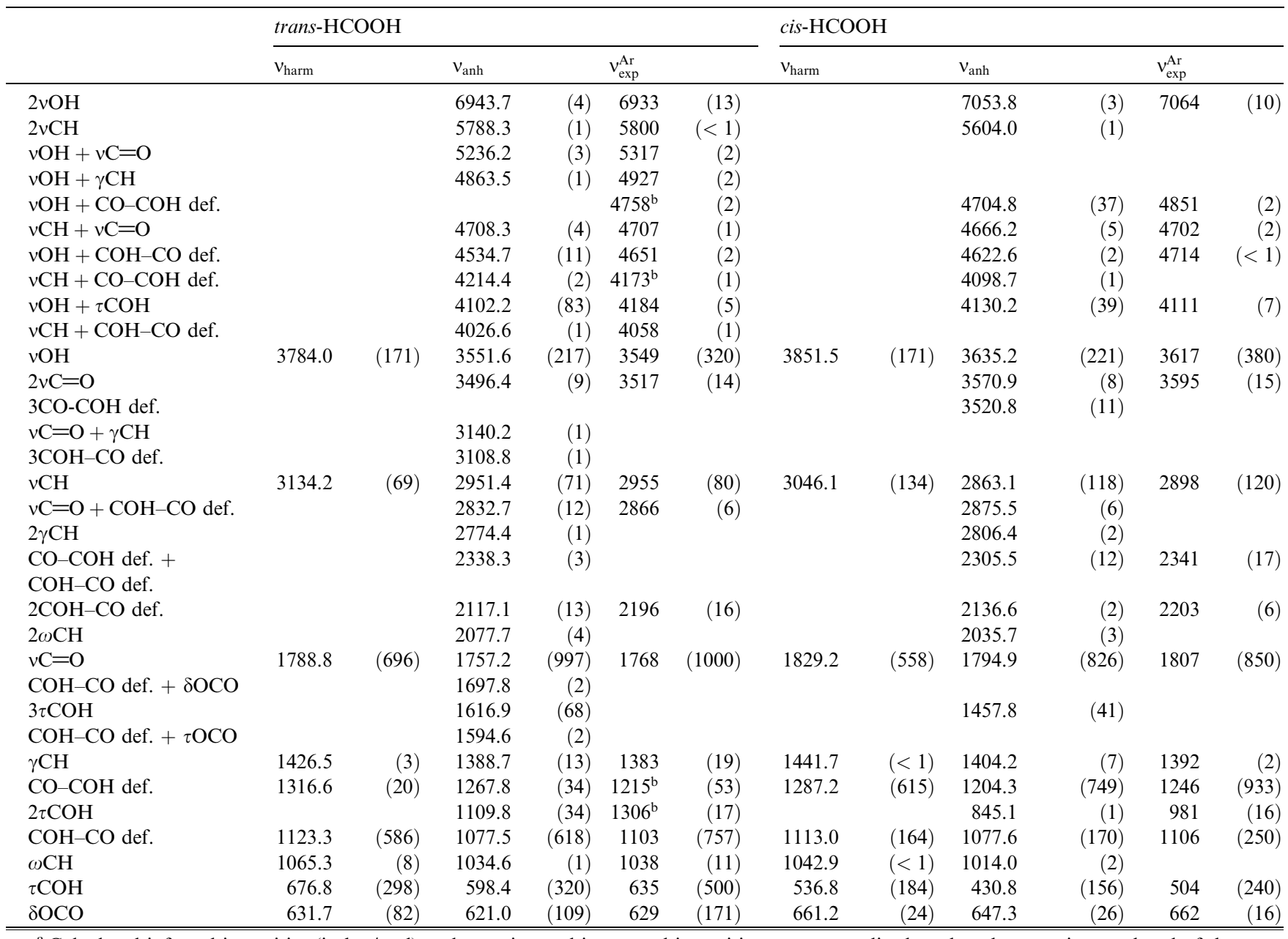

${ }^{\mathrm{a}}$ Calculated infrared intensities (in $\mathrm{km} / \mathrm{mol}$ ) and experimental integrated intensities were normalized so that the most intense band of the trans conformer has an intensity of 1000 . After this procedure all the predicted combination and overtone bands with intensities less than 1 are omitted. Experimental band positions correspond to the average value of the observed bands for the molecules isolated in two matrix-sites. The intensities of the anharmonic vibrations were obtained from Hartree-Fock wave functions in the CC-VSCF calculations.

${ }^{\mathrm{b}}$ Bands involved in Fermi resonance coupling. These bands should not be compared with the calculated values.

and thus in many cases the coupling constants are overestimated. There can be several reasons for the discrepancy of the observed and computed vibrational frequencies. The CC-VSCF calculations involve an approximation of separability of normal coordinates used to describe the vibrational motions of the molecule [2325]. Therefore, if strong couplings exist between modes the CC-VSCF calculations are not able to reproduce these motions. Also, the wide-amplitude vibrational modes, like the torsion in formic acid, seem to be hard to describe sufficiently well. Additionally, it must be remembered that the computational level used here (MP2/6-311++G(2d,2p)) could prove less reliable for configurations further away from the equilibrium structure. All in all, the CC-VSCF method is able to reproduce the experimental characteristics of formic acid on a qualitative level and it is more suitable to support experimental identification of molecular species than the standard harmonic vibrational calculations.

\section{Conclusions}

Vibrational spectroscopic data on matrix-isolated cisand trans- $\mathrm{HCOOH}$ and $\mathrm{DCOOH}$ in different sites is presented. The $7900-4000 \mathrm{~cm}^{-1}$ spectral features for cis$\mathrm{HCOOH}$ are discussed for the first time. This study also presents for the first time the experimental vibrational spectra of $c i s$-DCOOH.

For trans-HCOOH all but two of the CC-VSCF predicted binary combinations and first overtones in the $7000-4000 \mathrm{~cm}^{-1}$ region were detected. For cis- $\mathrm{HCOOH}$ about half of the expected modes were observed, in spite of the presence of this conformer in the matrix in a lower 
concentration. A very strong Fermi resonance between $v \mathrm{C}=\mathrm{O}$ and $2 \omega \mathrm{CD}$, previously reported for trans$\mathrm{DCOOH}$, was also found to be present in the cis conformer. The observed combinations of these two modes with the $\mathrm{vOH}$ were also found to be involved in Fermi resonance.

From the site-selective data, we conclude that the cage potential affects significantly the guest intermode coupling. The effect of local morphology on the anharmonicity and intermode couplings was found to be comparable with the effect of going from the gas phase to the solid rare gas environment. Therefore, we expect an important contribution from the local environment to the dynamics of processes involving intramolecular vibrational redistribution and relaxation in solid phase.

The CC-VSCF calculations reproduce reasonably well the experimentally observed positions of the fundamental frequencies, excluding the skeletal deformation modes and the torsional vibration. The coupling constants are overestimated by the calculations. The absolute shifts from the experimental values for the combination bands and overtones are twice as high as the ones for fundamentals, nevertheless, the relative error is still small $(\approx 3 \%)$. The systematic underestimation of the vibrational frequencies might be an indication that the $a b$ initio potential energy surface used is too "soft." Despite of that, the CC-VSCF calculations were shown to be superior to the standard harmonic vibrational predictions, and their ability to contribute to the assignment of overtone and combination modes appears as a valuable tool to aid the experimental work.

\section{Acknowledgments}

The Academy of Finland and Finnish Cultural Foundation are thanked for financial support. E.M. and R.F. acknowledge the Portuguese Foundation for Science and Technology (Ph.D. grant SFRH/BD/4863/2001 and project POCTI7433667QUI/2001). Prof. Benny Gerber and Dr. Galina Chaban are thanked for discussions on the anharmonic vibrational calculations

\section{References}

[1] S.-Y. Liu, D.M. Mehringer, L.E. Snyder, J. Astrophys. 552 (2001) 654-663.
[2] A. Goldman, F.H. Murcray, D.G. Murcray, C.P. Rinsland, Geophys. Res. Lett. 11 (1984) 307-310.

[3] B. Elves, S. Hawkins, M. Ravenscroft, J.F. Rounsaville, G. Schulz (Eds.), Ullmann's Encyclopedia of Industrial Chemistry, vol. A12, fifth ed., VCH, Germany, 1989.

[4] R.C. Millikan, K.S. Pitzer, J. Chem. Phys. 27 (1957) 1305-1308.

[5] I.C. Hisatsune, J. Heicklen, Can. J. Spectrosc. 18 (1973) $135-142$.

[6] G.M.R.S. Luiz, A. Scalabrin, D. Pereira, Infrared Phys. Technol. 38 (1997) 45-49.

[7] T.L. Tan, K.L. Goh, P.P. Ong, H.H. Teo, J. Mol. Spectrosc. 198 (1999) 110-114, and references therein.

[8] J.E. Bertie, K.H. Michaelian, J. Chem. Phys. 76 (1982) 886-894.

[9] T. Miyazawa, K.S. Pitzer, J. Chem. Phys. 30 (1959) 1076-1086.

[10] R.L. Redington, J. Mol. Spectrosc. 65 (1977) 171-189.

[11] D.O. Henderson, Doctoral Thesis, Texas Technical University, 1987.

[12] F. Madeja, P. Markwick, M. Havenith, K. Nauta, R.E. Miller, J. Chem. Phys. 116 (2002) 2870-2878.

[13] H. Morita, S. Nagakura, J. Mol. Spectrosc. 41 (1972) 54-68.

[14] M. Freytes, D. Hurtmans, S. Kassi, J. Liévin, J. Vander Auwera, A. Campargue, M. Herman, Chem. Phys. 283 (2002) 47-61.

[15] W.M. Hocking, Z. Naturforsch 31A (1976) 1113-1121.

[16] P.G. Blake, H.H. Davies, G.E. Jackson, J. Chem. Soc. B (1971) 1923.

[17] M. Pettersson, J. Lundell, L. Khriachtchev, M. Räsänen, J. Am. Chem. Soc. 119 (1997) 11715-11716.

[18] K.B. Wiberg, K.E. Laidig, J. Am. Chem. Soc. 109 (1987) 5935 5943.

[19] J.D. Goddard, Y. Yamaguchi, H.F. Schaefer III, J. Chem. Phys. 96 (1992) 1158-1166.

[20] M. Pettersson, E.M.S. Maçôas, L. Khriachtchev, J. Lundell, R. Fausto, M. Räsänen, J. Chem. Phys. 117 (2002) 9095-9098.

[21] S. Sander, H. Willner, L. Khriachtchev, M. Pettersson, M. Räsänen, E.L. Varetti, J. Mol. Spectrosc. 203 (2000) 145-150.

[22] L. Khriachtchev, J. Lundell, E. Isoniemi, M. Räsänen, J. Chem. Phys. 113 (2000) 4265-4273.

[23] J.O. Jung, R.B. Gerber, J. Chem. Phys. 105 (1996) $10332-10348$.

[24] J.O. Jung, R.B. Gerber, J. Chem. Phys. 105 (1996) 10682-10690.

[25] G.M. Chaban, J.O. Jung, R.B. Gerber, J. Chem. Phys. 111 (1999) $1823-1829$.

[26] G.M. Chaban, J.O. Jung, R.B. Gerber, J. Phys. Chem. A 104 (2000) 2772-2779.

[27] J. Lundell, M. Räsänen, Z. Latajka, Chem. Phys. 189 (1994) 245 260.

[28] J. Lundell, Chem. Phys. Lett. 266 (1997) 1-6.

[29] M.W. Schmidt, K.K. Baldridge, J.A. Boatz, S.T. Elbert, M.S. Gordon, J.H. Jensen, S. Koseki, N. Matsunaga, K.A. Nguyen, S.J. Su, T.L. Windus, M. Dupuis, J.A. Montgomery, J. Comput. Chem. 14 (1993) 1347-1363.

[30] E. Bjarnov, W.M. Hocking, Z. Naturforsch. 33A (1978) 610-618.

[31] R. Fausto, A.E. Batista de Carvalho, J.J.C. Teixeira-Dias, M.N. Ramos, J. Chem. Soc. Faraday Trans. 85 (2) (1989) 1945-1962.

[32] G.S. Devendorf, M.-H.A. Hu, D. Ben-Amotz, J. Phys. Chem. A. 102 (1998) 10614-10619. 